\title{
The Work of Culture
}

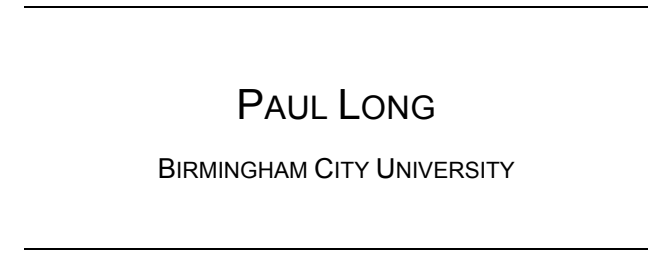

Tony Bennett and John Frow (eds), The Sage Handbook of Cultural Analysis

Sage, Los Angeles, London, New Delhi and Singapore, 2008

ISBN 9780761942290

RRP £95.00, US\$150.00

Austerity measures have yet to bite when it comes to the wealth of available handbooks, dictionaries, textbooks, solo-authored works or readers that address cultural studies, whether as a distinct field or where culture is appended to other disciplines, fields and methodologies. What claims for distinctiveness, attention and utility, then, underwrite the appearance of yet another addition to this prodigious market?

Firstly, it should be noted that many of those familiar from the pages and editorial board of this journal contributed essays to the collection under review, underwriting its authority and literal heavyweight status. Including the editors, thirty-eight authors contribute thirty-three chapters and four introductory essays in over seven hundred pages of double-column print. This is not a handbook for the back pocket. Secondly, this book had a long gestation: the project commenced in 2001 and has a publication date of 2008, although it arrived before this reviewer this year. In that glutted market, where one suspects that some material is herded 
quickly into print in order to capture ever decreasing niches and market shares, such care and attention count for a lot.

As Bennett and Frow point out in their introduction, this is not a handbook of cultural studies. Instead, it incorporates that field as one within an exploration of the way in which culture has been enlisted to do increasing amounts of analytical work across social sciences and humanities over the last three decades. There is a rehearsal of tensions in the explanatory force of culture in relation to perennial issues of its definition and conceptual elasticity, a character enlisted to productive ends in this pithy discussion and in the organisation of this book. Citing Ann Swidler and Richard Biernacki in turn, the editors present culture as something to be viewed beyond abstraction or a store of material, it is always 'in use', enacted rather than thought, a 'doing' rather than a 'believing'. (13) Without aiming for a compact definition then, the editors selected and briefed their authors to map various 'logics of culture' and its mobilisation in light of its growing importance and its impact upon discrete disciplinary assumptions, intellectual foundations and traditions. Kay Anderson's review of cultural geography is indicative in observing that her field has been swept up in the energy of this turn:

In its wake, geography's disciplinary engagement with culture has been redistributed well beyond the concerns of those who identify themselves as 'cultural' geographers per se. There have even been suggestions that 'the cultural' has colonized human geography, as economic, political and social geographers inform their analyses with questions of discourse, identity, meaning and representation. (46)

Organised into three sections, the handbook first offers Frameworks of Analysis, wherein the cultural turn and its articulations are accounted for in anthropology, human geography, psychology and history. Text-based fieldsliterary studies, music, film, art, broadcasting-are explored thereafter, as well as the boundary-crossing perspectives of cultural studies, feminism and material culture. Also explored is the role of the cultural in science studies. The brief for each writer was not for an exhaustive 'Olympian' overview but to write with 'an edge' in reviewing and assessing the characteristics of each field or topic 'from the vantage point of their own position within the contemporary debates'. (18) Thus, it is suggested that some of the theoretical logics of debate captured in this section, if not 
in the handbook as a whole, are likely to radically unsettle the foundations of cultural analysis outlined across familiar narrative terrain and genealogies. Certainly, the implications of current thought, agendas and methods give some authors cause to reflect on future directions in cultural analysis. In Daniel Miller's chapter on material culture for instance, he suggests that labels such as 'social sciences' reflect 'the Durkheimian vision of secular humanism predicated in moral, academic and conceptual terms as primordially social'. (287) He ponders how the concept of society is suffering the same kind of crisis that previously undermined the divine as a structuring concept. In turn, this has implications for disciplines in which the study of material culture has thus far functioned as a subsection and where it now threatens to upend this arrangement, where its concern is 'as much with how things made people as with how people made things'. (287) The success or otherwise of such challenges do at least counter suspicions that handbooks like this do little more than retrace the well-trod ground they share with so many others of the genre.

'Current Issues' indicates the scope of the second section of crossdisciplinary themes. Of concern here are the nation, modernity, globalisation and various modes of identity as well as the institutional, industrial and technological aspects of culture. As the editors state, many of these issues may not, at first glance, appear to be about the cultural although each accounts for its role in a variety of modes of organising the social world. Thus, Tim Mitchell's chapter on culture and economy is helpful in illuminating and thinking beyond the conventional polarity by which both are viewed. He summarises alternative approaches to conceptualising the 'making of the economy' that have emerged in recent years. These approach the economy as more than a universal and visible feature of any society but as:

a set of metrological projects that came to dominate the politics of the middle and later decades of the twentieth century [making] it possible to trace the way that these projects were often intertwined with the reformulation of culture as an array of collective resources to be managed and a new set of fields for the government of conduct. (463)

Mitchell's chapter offers a provocative outline for considering current perceptions and perspectives on an economy in crisis, the impasse in conceptualising an 
alternative to the status quo, as well as for exploring current demands for measures of the value of culture.

In 'Culture and Modernities', Joel S. Kahn notes the 'renewed preoccupation' with his subject and the apparent impossibility of conceiving of modernity nowadays outside of cultural terms. Here, he evaluates the challenge to universalising ideas of development presented by emergent modernities-explored in detail through an understanding of the Malaysian situation. While the tone and attack is an example perhaps of the 'edge' that the book aims for, Kahn's take on the modern is also valuable in directing one to think of such collections as barometers of the waxing and waning influence of particular concepts, methods and theorists which are revealed in the intellectual foundations of chapters. Turning to the index, it is noticeable for instance that no substantive space is devoted to the idea of the postmodernism as a distinct issue in need of particular treatment. Thus, Baudrillard and Lyotard, as two once star-turns, appear in only a smattering of references although Jameson is more widely cited. One finds a continued place for discussion of Adorno and Geertz, Bourdieu and Foucault are ubiquitous, while the work of Bruno Latour is influential across a number of chapters. While the contemporary argot of new media is present in the form of internet, cyber-this and that, 'digital' does not figure as a meaningful concept in need of indexing. Likewise, reference to 'fundamentalism' is absent while 'neoliberalism' does not figure as a prodigious point of reference. While this is one 'rough and ready' distillation that echoes an assessment conducted by the editors in evidencing the cultural turn, such anchors are as helpful in locating what kind of moment is captured by this book and a further, sometimes unstated, dimension of its challenge.

Research Theory and Practice is the third and shortest section. Avoiding offering a comprehensive 'methods manual' that would underwrite adventures prompted by preceding chapters, the brief for authors was to focus on areas of political contention in theory and practice and as a result some discontents and challenges are voiced. Dealing with anthropological practices for instance, Johannes Fabian and Vincent de Rooij conclude with an impassioned section on ethical considerations, and a complaint about the tendency of 'hit-and-run' relationships between researcher and interlocutor. They challenge the automatic ascription of anonymity for subjects, which, although sometimes unavoidable, is a practice which 
they suggest denies to them their historical status and agency. Likewise, they insist that researchers need to make their work available to their interlocutors, publishing as much as possible online and, in so doing, raising questions about authorship, ownership and affect in the relationship between the two. Alongside such assessments of qualitative approaches, Justin Lewis makes a case for the use of statistical methods in cultural analysis. He presents a cogent critique of dismissals of statistical analysis as in some way in thrall to power, noting that ignorance of the value of quantitative data can also undermine the nature of political challenges: 'If statistics play an important role in stories of control, dominance or hegemony, that is because they are a tool of storytelling, not because there is anything intrinsically hegemonic about the use of numbers.' (655)

I draw attention to Lewis's chapter as he anticipates that his argument will have to counter a general hostility to quantitative methods in cultural analysis among readers and in doing so underlines the uneven invitations of this kind of book. As a reviewer acting on behalf of a potential readership, one is tempted to flatter oneself as expert on one hand, examining coverage of familiar ground for reassurance of one's learning and understanding. On the other hand, one necessarily overcomes one's prejudices-by responding to arguments like Lewis's—or admits ignorance by exploring a wealth of unknown territories in order to assess a handbook's utility. For this reader then, its variety, familiarity and originality works well, although it is inevitable that many of the chapters have a 'dormant' function which means they will be called upon, re-read and engaged with when needed. In this way, the full value of this handbook is likely to be revealed over a long period of use and familiarity.

In a nice touch of editorial organisation, a final chapter from Pepi Leistyna explores cultural activism, focusing on the global justice movements and the potential of new technologies in reinventing activism. This is an optimistic and celebratory account of action-based research and how theory has informed activism, noting some real political impact and social gains, yet a little lacking in a detailed critical view of some dead-ends in such a relationship. The domain of this chapter as well as some of the unaddressed motivations behind so many ideas in this book suggests perhaps that what might have been a useful addition to its pages would be a chapter offering a systematic cultural analysis of cultural analysis itself, of its 
political assumptions, practice and pedagogies, and indeed its place in the academy. An issue raised in Mike Savage's comment in his chapter on culture and class is one such instance that prompts what I have in mind:

If leading academics think that the cultural importance of class is declining, this can better be read as a telling commentary on the nature of the contemporary academic career rather than as a perceptive means of addressing the contemporary situation. (467)

Nonetheless, for some readers, Leistyna's chapter would not be a bad place to start with in this admirable book, and is certainly worth recommending to those new to cultural analysis or in need of its insights. Like most of the chapters in this work, Leistyna's extensive overview is well managed in its detail, illuminating in its insights and will be read like a provocative dispatch from an intellectual frontline. The book as a whole will be read avidly by many in the overtaxed outposts of cultural analysis and its teaching and who will admire its scholarship, insight and deft execution. Ultimately it will serve to underwrite the attention to the work of culture, offering a way into its study, exploration of what is involved as well as challenges to how it is maintained.

Paul Long is Reader in Media and Cultural History in the Birmingham School of Media at Birmingham City University. His research interests encompass the creative and cultural industries, popular music culture, media histories and archiving. He is the author of 'Only in the Common People': The Aesthetics of Class in Post-War Britain (2008). 